\title{
PROTOCOLO DE ATENDIMENTO E PATOLOGIAS BUCAIS EM PACIENTES COM INSUFICIÊNCIA RENAL CRÔNICA
}

Caroline de Souza Gomes BRANDÃO; Talita Farias MIKSZA; Rafaela Casagrande FIGLARZ

Insuficiência renal crônica (IRC) trata-se de uma redução da função renal que se não tratada pode evoluir para a completa perda funcional do órgão. A população com IRC sofre ainda de patologias secundárias como diabetes, hipertensão arterial, hepatite entre outras necessitando de cuidados especiais também no atendimento bucal. As patologias bucais que mais acometem esses pacientes são estomatites, candidiase, problemas periodontais, xerostomia, osteodistrofia radial (SANCHES, 2004). Esse trabalho tem por objetivo elucidar sobre o protocolo de atendimento a pacientes com insuficiência renal crônica e terapêutica medicamentosa utilizada, criado pela Fundação Pro Renal (uma instituição sem fins lucrativos que atende pacientes transplantados, em diálise peritonial, hemodiálise e ambulatório através de uma equipe multiprofissional que inclui médicos, podólogos, assistente social, psicólogo, fisioterapeuta e cirurgiões-dentistas) e os principais acometimentos dentre as patologias bucais a pacientes IRC, plano de tratamento através de revisão de literatura e em abordagem de casos clínicos. 